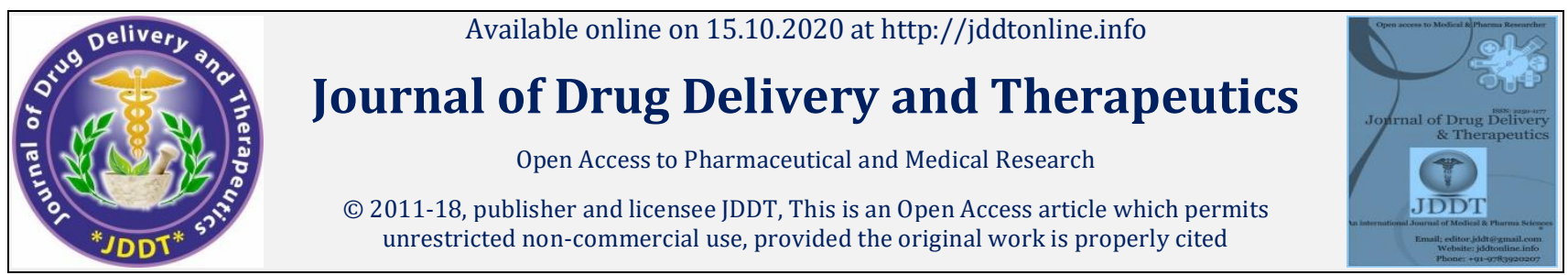

Open Access

Review Article

\title{
Solid Lipid Nanoparticle for the Delivery of Docetaxel: A Review
}

\author{
Agrawal Pranav*, Tatode Amol, Umekar Milind \\ Smt. Kishroitai Bhoyar College of Pharmacy, Department of Pharmaceutics, Kamptee, Nagpur, Maharashtra, India-441002
}

\begin{abstract}
Solid lipid nanoparticles are the forefront of the rapidly developing field of nanotechnology with several potential applications in drug delivery, clinical medicine and research. Due to its solid state it has greater stability than other nanocarrier systems. There are several other advantages like sustained release, improves bioavaibility and delivery of poorly water soluble drugs, helps in control of several pharmacokinetic parameters of drugs due to which use of SLN is increasing day by day. Various techniques can be used for the formulation of SLN i.e. solvent evaporation, microemulsification technique, high pressure homogenization and supercritical fluid method. It has several applications likes it is use in gene transfer therapy, also use in different drug delivery systmer like oral and pulmonary drug delivery system. Due to several advantages SLNs are widely used in chemotherapy for the treatment of the cancer. The use of SLN for the delivery of Docetaxel to tumor site have several benefits likes site specific delivery, less toxic effect, more cell cytotoxicity and more bioavaibility which leads to decrease in the dosing frequency. Docetaxel is an anticancer agent extracted from plant Taxus Baccata which is widely used in chemotherapy to treat cancer. This article contains the detail information of about the advantages, disadvantages, different method of preparation and several SLN loaded with Docetaxel.
\end{abstract}

Keywords: Solid lipid nanoparticles, drug delivery, clinical medicine, poorly water soluble drugs

Article Info: Received 10 Aug 2020; Review Completed 15 Sep 2020; Accepted 23 Sep 2020; Available online 15 Oct 2020

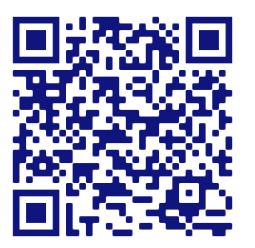

\section{Cite this article as:}

Agrawal P, Tatode A, Umekar M, Solid Lipid Nanoparticle for the Delivery of Docetaxel: A Review, Journal of Drug Delivery and Therapeutics. 2020; 10(5-s):224-228 http://dx.doi.org/10.22270/jddt.v10i5-s.4441

*Address for Correspondence:

Agrawal Pranav, Smt. Kishroitai Bhoyar College of Pharmacy, Department of Pharmaceutics, Kamptee, Nagpur, Maharashtra, India-441002

\section{Introduction}

Colloidal particles ranging in size between 10 and $1000 \mathrm{~nm}$ are known as nanoparticles. They are manufactured from synthetic or natural polymers and ideally suited to optimized drug delivery and reduce toxicity. Over the years, they have emerged as a variable substitute to liposome as drug carrier. The successful implementation of nanopartilces for drug delivery depends on their ability to penetrate across the cell membrane, sustained release of their contents and their stability ${ }^{1}$. There are several disadvantages of liposome or traditional nanoparticles like stability, leakage of drug from the dosage form, etc. to overcome these problem Solid lipid nanoparticles was developed. SLN are colloidal carriers developed in the last decade as an alternative system to existing traditional carrier such as emulsion, liposomes and polymeric nanoparticles. They are a new generation of submicron-sized lipid emulsion where the liquid lipid has been substituted by solid lipid. SLN offer unique properties such as small size, large surface area, high dose loading and the interaction of phases at the interfaces and are attractive for potential to improve performance of pharmaceuticals, neutraceuticals and other materials as well as increase stability is the most important advantage of SLN. SLN are sub-micron colloidal carrier which is composed of physiological lipid, dispersed in water or in an aqueous surfactant solution. The use solid lipid instead of liquid lipid is beneficial as it has been shown to increase control over the release kinetics of encapsulated compounds and to improve the stability of incorporated chemically-sensitive lipophilic ingredients. The benefit of using solid lipids is due to several physiochemical properties of lipid. Firstly, the mobility of reactive agents in solid matrix is lower than in a liquid matrix and so the rate of chemical degradation reactions may be retarded. Secondly, micro phase separations of the active ingredients and carrier lipid within individual liquid particles can be controlled, thereby preventing the accumulation of active compounds at the surface of lipid particles where chemical degradation reactions often occur. There is also another benefit; the absorption of poorly absorbed drugs has been shown to be increased after incorporation into solid lipid nanoparticles ${ }^{2}$.

Due to several benefits SLN are used for various types of drugs like antineoplastic agents, delivery of several protein and peptide, antiepileptic agents, etc. Cancer is one of the 
most dangerous disease that threaten the health of human around the world There are various therapeutic options for the treatment of cancer like surgery, radiation, immunological, hormone, chemotherapy and stem cell transplant. From all of this option chemotherapy is the choice of therapeutic treatment option due to several benefits $^{3}$. In chemotherapy cancer treatment one or more antineoplastic agents are used according to individual's factors. The various classes of drugs used in chemotherapy are Taxanes (paclitaxel, docetaxel), antibiotics (doxorubicin, mitoxantrone), EGF receptor inhibitors (gefitinib, cetuximab), Glucocorticoids (prednisolone), Folate antagonist (methotrexate, pemetrexed) and Monoclonal antibody (rituximab) ${ }^{4}$. The various side effects includes hair loss, nerve pain, anemia, appetite loss, edema, lymphedema, sexual health issues, skin and nail change, sleep problem, urinary and bladder problem, fertility issues, etc. The major side effect of chemotherapy is the inability to deliver specific drug to the target which cause drug to affect both healthy as well as cancerous cells ${ }^{5}$. Among all the taxane derivative paclitaxel (PTX) and docetaxel (DTX) is the most widely used anticancer agents. PTX is a potent antineoplastic agent frequently used for the treatment of wide variety of human malignancies such as breast, ovarian, lung and other cancer6. However, the use of PTX and DTX was limited due to its acquired drug resistant, side effect and poor aqueous solubility ${ }^{7}$. To minimize this problems many formulation has been developed such as use of liposomes of DTX $^{8}$, selfassembled micelles of $\mathrm{DTX}^{9}$, nanoemulsion of $\mathrm{DTX}^{10}$ nanoparticle of $\mathrm{PTX}^{11}$ and solid lipid nanoparticles using PTX $^{12}$.

\section{Advantages ${ }^{13,14,15}$}

1. SLN helps to achieve controlled as well as sustained release of several drugs.

2. It has better control over release kinetics of encapsulated compound small particle size and narrow size distribution helps in site specific drug delivery.

3. It improves bioavaibility as well protect light sensitive drugs from outer environment.

4. It also helps in delivery of poorly water soluble drugs

5. Encapsulation of drug helps in control over the several pharmacokinetic parameters.

6. Much easier to manufacture than biopolymeric nanoparticles.

7. It improves the stability of pharmaceuticals.

8. The transporter lipids are biodegradable and consequently protected. Avoidance of natural solvents. Enhanced bioavailabilities of inadequately water dissolve atoms.

\section{Disadvantages ${ }^{16}$}

1. Poor loading capacity

2. Drug expulsion after polymeric transition during storage

3. Due to partitioning effect during the production process it has low capacity to load hydrophilic drugs.

\section{Different techniques for the preparation of SLN}

\section{High pressure homogenization (HPH) ${ }^{17}$}

In high pressure homogenization it uses high pressure of 100-200 bar through narrow gap. The fluid is accelerated from a very short distance at very high velocity rate. This results in decrease of particle size to submicron range due to high rate of velocity. Two general approaches of HPH are hot homogenization and cold homogenization work on the same concept of mixing the drug in bulk of lipid melt.

\section{a. Hot homogenization-}

Hot homogenization is generally carried out at high temperature more than melting point of lipid. A pre emulsion of drug loaded lipid melt and the aqueous emulsifier at the same temperature is obtained by highshear mixing device. In general, high temperature helps in obtaining lower particle size due to the decrease in viscosity of the inner phase.

\section{b. Cold homogenization-}

There are various problems associated with hot homogenization techniques like temperature induced drug degradation, etc. To overcome these problems cold homogenization method is developed. In, this technique the drug containing lipid melt is cooled, this solid lipid is reduced in size which is further this micro particles are dispersed in a cold surfactant solution yielding a presuspension. This pre-suspension is homogenized at or below room temperature; the gravitational force breaks the solid micro particle to solid lipid nanoparticles.

\section{Micro emulsion based SLN preparation 18}

This technique is developed by Gas co and other scientist in 1993 for developing SLN having nanosize distribution (Gas co. 1993). In this method hot micro emulsion is dispersed in cold water usually in the ratio of $1: 25$ to $1: 50$. Ultra filtration is used for the removal of excess amount of water increasing the concentration of particle. Considering micro emulsion, the temperature gradient and $\mathrm{pH}$ value fix the product quality in addition to composition of micro emulsion. High temperature gradient helps in rapid lipid crystallization and prevents aggregation.

\section{Solvent evaporation 19}

In this technique, lipid and hydrophobic drug were dissolved in water immiscible solvent like cyslohexane, dichloromethane, toluene, etc. and that is emulsified in an aquesous phase using high speed homogenizer. This emulsion is further passed through microfluidizer to improve the efficiency of fine emulsification. The organic solvent is evaporated using mechanical stirring at room temperature and reduced pressure. This solvent evaporation will result in the formation of solid lipid nanoparticles.

\section{Solvent emulsification-diffusion method 20}

This technique can be carried in both the phase i.e. aqueous phase as well as oil phase using partially miscible with water. Firstly, both the solvent and water were mutually saturated in order to achieve thermodynamic equilibrium of both liquid. After this drug and lipid are dissolved in water saturated solvent the organic phase was emulsified with solvent saturated aqueous solution containing stabilizer using mechanical stirrer. Water is added in a particular ratio once the $\mathrm{o} / \mathrm{w}$ emulsion is formed in order to allow solvent diffusion into the continuous phase, thus forming aggregation of the lipid in the nanoparticles. The diffusion step was carried out either at room temperature or at the temperature under which the lipid was dissolved. Throughout the process constant stirring was maintained. Finally the diffused solvent was eliminated by vacuum distillation or lyophilization. 


\section{Supercritical fluid method 18}

In this method, a fluid is qualified as supercritical when its pressure and temperature exceed their respective critical value. Above the critical temperature, it is not possible to liquefy a gas by increasing the pressure. The supercritical fluid has unique thermo-physical properties. As the pressure is raised, the density of the gas increases without significant increase in the viscosity while the ability of the fluid to dissolve compounds also increases. A gas may have little to no ability to dissolve a compound under ambient condition can completely dissolve the compound under high pressure in supercritical range. Therefore, its solvent power is altered by careful changes in temperature and pressure. many gases like $\mathrm{CO}_{2}$, ammonia, ethane and $\mathrm{CH}_{2} \mathrm{FCF}_{3}$ were tried, but $\mathrm{CO}_{2}$ is the best option for SCF technique because, it is generally regarded as safe, easily accessible critical point, does not causes the oxidation of drug material, leaves no traces behind after the process, is inexpensive, noninflammable, environmentally acceptable an easy to recycle or to dispose off. In this technique generally, organic solvents are used because they are fully miscible in $\mathrm{SCF}_{-} \mathrm{CO}_{2}$. This process comprises several processes for nanoparticle production such as rapid expansion of supercritical solution, particles from gas saturated solution, gas/supercritical antisolvent, aerosol solvent extraction solvent, solution enhanced dispersion by supercritical fluid, supercritical fluid extraction of emulsion.

\section{Application of SLN-}

\section{Oral drug delivery applications $\mathbf{2}^{21}$}

Oral drug administration is the most preferable route of administration due to good patient compliance, noninvasiveness and therapeutic success, but poor water solubility of drug is limiting step for the absorption of them. Thus an approach is needed to improve the bioavailability of drugs.

\section{Lipid-based delivery system-}

In the recent decades have shown many advance for this purpose. Since in this system drug is dissolved in lipid which leads to increase in the solubility of poorly water soluble drug especially lipophilic drug. It also helps in decreasing the toxic effect of several drugs.

\section{Pulmonary drug delivery application 22}

SLN have several advantages in pulmonary drug delivery i.e. it can be easily incorporated into carriers which inhaled to the lungs, therefore able to provide a deep lung deposition, good adhesion and elongated retention in the lung. Also due to improved and prolonged therapeutic effects, SLN have a longer dosing interval and better patient compliance. Many studies are available about SLN as local delivery carriers or as systemic delivery carriers for small molecules and for macromolecules respectively by pulmonary administration.

\section{Gene transfer applications ${ }^{23}$}

Phospholipid is the most important component of cell membrane which helps SLN to penetrate across the membrane easily. This enhances the uptake of several genetic materials. Cationic SLN are interesting and proper nonviral gene delivery vector for systemic delivery. Genospheres have large potential for targeted gene delivery. Genospeheres generally carry material such as plasmid DNA, DNA and other nucleic acids.

\section{Cosmetic application ${ }^{24}$}

SLN are widely used in the cosmetic preparation due to several advantages. They are used as carrier in sunscreen, anti-acne and antiageing preparations. In fact due high control behavior of SLN on skin penetration of active substances, they have UV-blocking and skin hydration behavior.

\section{Food application-}

SLN are excellent potential carriers for sensitive compounds in food industry because they improve the industrial and the nutritional quality of a lipid containing food. Quality of them is affected by the lipid oxidation at storage and processing. Therefore, oxidants are used to prevent this problem.

\section{SLN loaded with Docetaxel-}

Docetaxel is an antineoplastic agent derived from the plant Taxus Baccata which is used for the treatment of various types of cancer such as colon cancer, colorectal cancer, small lung cancer, breast cancer and skin cancer. Due to several benefits docetaxel is widely used of the treatment of the cancer. Various types of SLN is formulated containing docetaxel. In 2009, a Chinese scientist developed SLN of docetaxel for the first time. They used homogenization techniques for the preparation of SLN using egg yolk phosphotidylcholine, dioleoylphophatidyl thanolamine, trimyristin and lactobionic acid. From the results of various evaluation tests, it was found that the cytotoxicity of SLN against hepatocellular carcinoma cell line BEL7402 was superior to Taxotere. It also shows better antitumor efficacy tolerant and antitumor effect in murine model bearing hepatoma. These results implied that this targeted nanocarrier of docetaxel coukd enhance its antitumor effect in vivo with low systemic toxicity for the treatment of locally advanced and metastatic HCC ${ }^{25}$. After this many other scientist also worked on the formulation of docetaxel loaded SLN some of them are listed below in Table I. 
Table I. Different types of SLN formulation loaded with DTX

\begin{tabular}{|c|c|c|c|c|}
\hline Sr. No. & Drug & Method & Key Ingredients & Conclusion \\
\hline 1. & Docetaxel & $\begin{array}{l}\text { Supercritical Fluid } \\
\text { Method }\end{array}$ & $\begin{array}{l}\text { Soya bean lecithin, } \\
\text { Poloxmer } 188 \text { and Glycerol } \\
\text { tristearate }\end{array}$ & $\begin{array}{l}\text { SLN shows elongated } t_{1 / 2} \text { and MRT compared } \\
\text { with Taxotere. It also shows potent anti-tumor } \\
\text { activity to ovarian carcinoma in vivo with less } \\
\text { toxicity }{ }^{26} \text {. }\end{array}$ \\
\hline 2. & Docetaxel & $\begin{array}{l}\text { Micro Emulsion } \\
\text { Technique }\end{array}$ & $\begin{array}{l}\text { Disterayl Phosphatidyl } \\
\text { Ethanolamine, soya } \\
\text { phosphatidylcholine }\end{array}$ & $\begin{array}{l}\text { It shows better cytotoxic effect on MDA-MB- } 453 \\
\text { breast cancer cell line. It is also proved for the } \\
\text { targeting efficacy for FGFR-127. }\end{array}$ \\
\hline 3. & Docetaxel & $\begin{array}{l}\text { Emulsion Solvent } \\
\text { Evaporation }\end{array}$ & $\begin{array}{l}\text { Betreliesoxybutyric acid, } \\
\text { Glyceryl monostearate, } \\
\text { Vitamin E, soy lecithin }\end{array}$ & $\begin{array}{l}\text { In vitro study sate the control released of drug. } \\
\text { Cell uptake study revealed the increase of } \\
\text { docetaxel with } \mathrm{SLN}^{28} \text {. }\end{array}$ \\
\hline 4. & Docetaxel & Super Critical Fluid & Compritol, precirol, H-SPC & $\begin{array}{l}\text { In vitro cytotoxicity studies on C- } 26 \text { and A- } 375 \\
\text { cells show the increase in cellular uptake as } \\
\text { compare with Taxotere. In vivo antitumor } \\
\text { inhibitory efficacy was carried out on C- } 26 \\
\text { implanted BALB/c mice and it showed better } \\
\text { tumor inhibitory efficacy and survival rate } 18 \text {. }\end{array}$ \\
\hline 5. & Docetaxel & $\begin{array}{l}\text { High Pressure } \\
\text { Homogenization }\end{array}$ & $\begin{array}{l}\text { Soyabean lecithin, } \\
\text { Trimyristin }\end{array}$ & $\begin{array}{l}\text { It showed lower toxicity as compare to Taxotere } \\
\text { and induced more apoptosis at } 24 \text { hours after } \\
\text { treatment in vitro }{ }^{17} \text {. }\end{array}$ \\
\hline 6. & Docetaxel & $\begin{array}{l}\text { Solvent Diffusion } \\
\text { Techniques }\end{array}$ & $\begin{array}{l}\text { Tween } 80 \text {, D-alpha- } \\
\text { tocopherol-succinate }\end{array}$ & $\begin{array}{l}\text { The oral bioavaibility and intestinal absorption } \\
\text { increases as compare to Taxotere } 20 \text {. }\end{array}$ \\
\hline 7. & Docetaxel & Solvent Evaporation & $\begin{array}{l}\text { DOPE-PEG-2000, } \\
\text { Phosphatidylcholine }\end{array}$ & $\begin{array}{l}\text { It shows higher antitumor activity on mouse as } \\
\text { compare to TaxoTer }{ }^{19}\end{array}$ \\
\hline 8. & Docetaxel & $\begin{array}{l}\text { Emulsion Solvent } \\
\text { Evaporation }\end{array}$ & $\begin{array}{l}\text { Soyabean Lecithin, Glecerol } \\
\text { monosterate, Tween } 80\end{array}$ & $\begin{array}{l}\text { It shows the higher cellular uptake in Cacp-2 } \\
\text { cells as compare to marketed formulation }{ }^{29} \text {. }\end{array}$ \\
\hline
\end{tabular}

\section{Conclusion}

In 1992, SLN was invented by Schwarz which was formulated using Dynasan (melted lipid), soya lecithin and poloxamer. The use of SLN is increasing day by day with several benefits like feasibility of incorporation of lipophilic and hydrophilic drug, improved physical stability, low cost, ease of scale-up and manufacturing. Also, site specific and sustain release of drug can be achieve with the use of SLN. Several methods of preparation has been developed to prepare SLN like emulsion solvent evaporation method, solvent evaporation, high pressure homogenization and microemulsion techniques. SLNs are relatively young delivery systems and hold great promise for their systemic investigation and explotitation.

\section{References}

1. Scheffel U, Rhodes BA, Natarajan TK, Wagner HN. Albumin microspheres for study of the reticuloendothelial system. J Nucl Med. 1972 Jul 1; 13(7):498-503.

2. Lingayat VJ, Zarekar NS, Shendge RS. Solid lipid nanoparticles: a review. Nanoscience and Nanotechnology Research. 2017 Apr; 2:67-72.

3. Li J, Yin T, Wang L, Yin L, Zhou J, Huo M. Biological evaluation of redox-sensitive micelles based on hyaluronic aciddeoxycholic acid conjugates for tumor-specific delivery of paclitaxel. International journal of pharmaceutics. 2015 Apr 10; 483(1-2):38-48.

4. Tripathi K D. 2014. Pharmacological Classification of Drugs: With Dose and Preparation. $5^{\text {th }}$ edition, Jaypee Brothers Medical Publishers Ltd. New Delhi.

5. Cancer.gov United of American: National Institue of Health; [Accesses December 25, 2016]. [updated 2016]. Available from: https://www.cancer.gov/types/breast/patient/breasttreatment-pdq.
6. Routh S, Nandagopal K. Patent survey of resveratrol, taxol, podophyllotoxin, withanolides and their derivatives used in anticancer therapy. Recent patents on biotechnology. 2017 Aug 1; 11(2):85-100.

7. Zhang X, Liang N, Gong X, Kawashima Y, Cui F, Sun S. Tumortargeting micelles based on folic acid and $\alpha$-tocopherol succinate conjugated hyaluronic acid for paclitaxel delivery. Colloids and Surfaces B: Biointerfaces. 2019 May 1; 177:11-8.

8. Han S, Sun R, Su H, Lv J, Xu H, Zhang D, Fu Y. Delivery of docetaxel using $\mathrm{pH}$-sensitive liposomes based on $\mathrm{D}-\alpha$ tocopheryl poly (2-ethyl-2-oxazoline) succinate: Comparison with PEGylated liposomes. Asian Journal of Pharmaceutical Sciences. 2019 Jul 1; 14(4):391-404.

9. Jiang $\mathrm{S}$, Mou Y, He H, Yang D, Qin L, Zhang F, Zhang P. Preparation and evaluation of self-assembly Soluplus ${ }^{\circledR}$ sodium cholate-phospholipid ternary mixed micelles of docetaxel. Drug development and industrial pharmacy. 2019 Nov 2; 45(11):1788-98.

10. Verma P, Meher JG, Asthana S, Pawar VK, Chaurasia M, Chourasia MK. Perspectives of nanoemulsion assisted oral delivery of docetaxel for improved chemotherapy of cancer. Drug delivery. 2016 Feb 12; 23(2):479-88.

11. Ley J, Wildes TM, Daly K, Oppelt P, Adkins D. Clinical benefit of nanoparticle albumin-bound-paclitaxel in recurrent/ metastatic head and neck squamous cell carcinoma resistant to cremophor-based paclitaxel or docetaxel. Medical Oncology. 2017 Feb 1; 34(2):28.

12. Baek JS, Shin SC, Cho CW. Effect of lipid on physicochemical properties of solid lipid nanoparticle of paclitaxel. Journal of Pharmaceutical Investigation. 2012 Oct 1; 42(5):279-83.

13. Shagufta khan, Solid lipid nanoparticles a review World Journal of Pharmacy and Pharmaceutical Sciences, volume 1, may 2012, 96-115.

14. Ekambaram, Abdul Hasan Sathali A and Priyanka K, solid lipid nanoparticles and lipid nanostructures overview, scientific Review \&Chemical communication, 2011; 2:216-220 
15. Rawat, Jain MK, Singh A, Studies on binary lipid matrix based solid lipidnanoparticles of repaglinide, In vitro and in vivo evaluation, Journal of Pharmaceutical Sciences, 2011; 2:66-78.

16. Ramteke, K., Joshi, S. and Dhole, S., "Solid Lipid Nanoparticle: A Review”, IOSR Journal of Pharmacy, 2012; 2(6):34-44.

17. Yuan Q, Han J, Cong W, Ge Y, Ma D, Dai Z, Li Y, Bi X. Docetaxelloaded solid lipid nanoparticles suppress breast cancer cells growth with reduced myelosuppression toxicity. International journal of nanomedicine. 2014; 9:4829.

18. Mosallaei N, Jaafari MR, Hanafi-Bojd MY, Golmohammadzadeh S, Malaekeh-Nikouei B. Docetaxel-loaded solid lipid nanoparticles: preparation, characterization, in vitro, and in vivo evaluations. Journal of pharmaceutical sciences. 2013 Jun 1; 102(6):1994-2004.

19. Naguib YW, Rodriguez BL, Li X, Hursting SD, Williams III RO, Cui Z. Solid lipid nanoparticle formulations of docetaxel prepared with high melting point triglycerides: in vitro and in vivo evaluation. Molecular pharmaceutics. 2014 Apr 7; 11(4):1239-49.

20. Cho HJ, Park JW, Yoon IS, Kim DD. Surface-modified solid lipid nanoparticles for oral delivery of docetaxel: enhanced intestinal absorption and lymphatic uptake. International journal of nanomedicine. 2014; 9:495.

21. Pandey R, Sharma S, GKhuller GK. Oral SLN Based antitubercular chemotherapy, Tuberculosis (Edinb) 2005; 85:415-420.

22. Cavalli, R., Gasco, M.R., Chetoni, P., Burgalassi, S., Saettone, M.F. Solid lipid nanoparticles (SLN) as ocular delivery systems for tobramycin. Int J Pharm 2002; 238: 241-5.
23. Rudolph C, Schillinger U, Ortiz A, Tabatt K, Plank C, Muller RH, Application of novel Solid lipid nanoparticles (SLN) - gene vector formulations based on a diametric HIV-1 VAT - peptide in vitro and in vivo.Pharmaceutic Res, 2004; 21:1662-1669.

24. Wissing SA, Muller RH, Solid lipid nanoparticles (SLN) a novel carrier for U V blockers. Pharmazie 56, 2001, 783-786.

25. Xu Z, Chen L, Gu W, Gao Y, Lin L, Zhang Z, Xi Y, Li Y. The performance of docetaxel-loaded solid lipid nanoparticles targeted to hepatocellular carcinoma. Biomaterials. 2009 Jan 1; 30(2):226-32.

26. Zhang P, Chen L, Zhang Z, Lin L, Li Y. Pharmacokinetics in rats and efficacy in murine ovarian cancer model for solid lipid nanoparticles loading docetaxel. Journal of nanoscience and nanotechnology. 2010 Nov 1; 10(11):7541-4.

27. Pathak A, Tanmay $M$, Murthy RS. Development and characterization of docetaxel loaded anti-FGFR-1 modified solid lipid nanoparticles for breast cancer targeting. Int J Adv Pharm Biol Chem. 2012; 1:381-7.

28. Venishetty VK, Komuravelli R, Kuncha M, Sistla R, Diwan PV. Increased brain uptake of docetaxel and ketoconazole loaded folate-grafted solid lipid nanoparticles. Nanomedicine: Nanotechnology, Biology and Medicine. 2013 Jan 1; 9(1):11121.

29. Shi LL, Xie H, Lu J, Cao Y, Liu JY, Zhang XX, Zhang H, Cui JH, Cao QR. Positively charged surface-modified solid lipid nanoparticles promote the intestinal transport of docetaxel through multifunctional mechanisms in rats. Molecular pharmaceutics. 2016 Aug 1; 13(8):2667-76. 